\title{
Design of a New Carrying Device Based on the Stair Handrail
}

\author{
XuChunlei ${ }^{1, a}$ \\ ${ }^{1}$ School of Electrical and Electric Engineering, North China Electric Power University, Beijing, \\ 102206, China \\ axuchunlei961016@163.com
}

Keywords: Stair Handrail, Power Assisting Device, Ratchet Mechanism, Folding Mechanism

\begin{abstract}
This paper describes a power assisting device with the help of the stair handrail. The slope of the stair handrail not only changes the forced direction of the objects, but also changes the ways of putting strength. The adjustable clamp system can adapt to different types of stair handrails. The fixed device canprevent it from tilting. The brake mechanism can control the gliding speed of the device. And the ratchet wheel can prevent the device from sliding down. In addition, the device is foldable, not only can it transport with the help of the stair handrail, but also i t can transport on the ground, so the course of the transit is more convenient and fluent.
\end{abstract}

\section{Introduction}

In recent years, with the rapid development of economy and the rise of e-commerce, express delivery industry works up as anemerging service industry.However, the distribution form of the express company is still manpower, so couriers' workload is heavy. Most delivery companies adopt "door-to-door" service mode, however, most of the old residential buildings are no elevators at present.A portable power device is needed especially when couriers need to transport large commodities upstairs. The most widely applicabledeliverydevicenowadays isplanetary wheeldolly.This kind of stair climbing dolly has high noise, large vibration amplitude, unstable performance, low efficiency and so on, which has inevitable shortcomings to deliver large commodities.

In view of this, I design a new carrying device based on the stair handrail to help couriersexpress goods, this device can not only lighten the working strength of couriers when transport goods upstairs, but also can ensure the safety of the goods. Couriers send the goods to people who live upstairs conveniently. In addition, this device can also be used to transport goods on the ground.

\section{The Design Principle}

The device contacts with the stair handrailby means of the side wheels and the top wheel. The side wheels fix with the stair handrail tightly by means of the spring. Select the spring with appropriate stiffness factor which can fix with different types of the stair handrail. The top wheel connects to the ratchet wheel which can prevent the device from sliding down. The clamping mechanismconnects to the fixed device can prevent the goods from sliding off the device. The reliability of the delivery is ensured. Simultaneously,the brake mechanism can control the gliding speed of the device.And the ratchet wheel which is on the handle can prevent the device from sliding down. The device is foldable on account of the hinge and the connecting rod.

The three-dimensional diagramand the real picture of the deviceare as follows: 


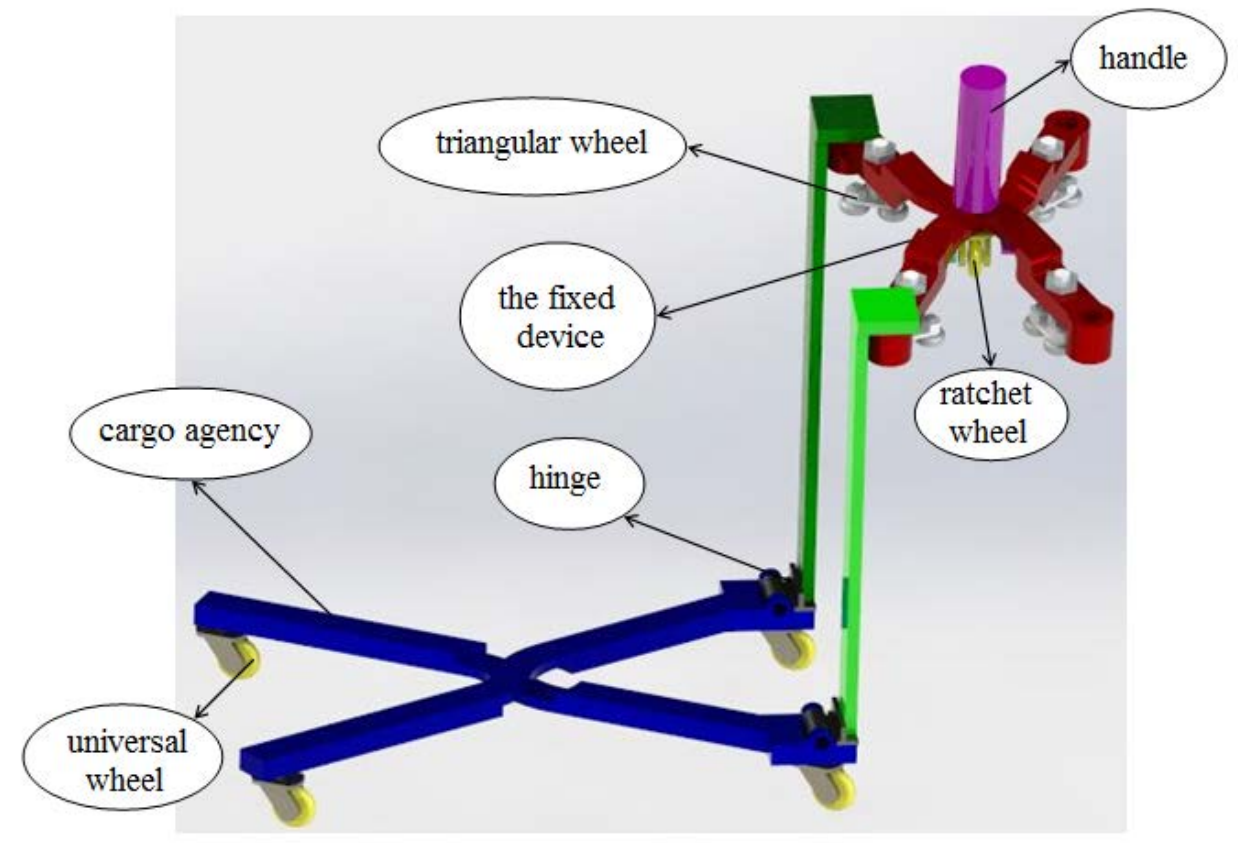

Fig.1The three-dimensional diagram of the device
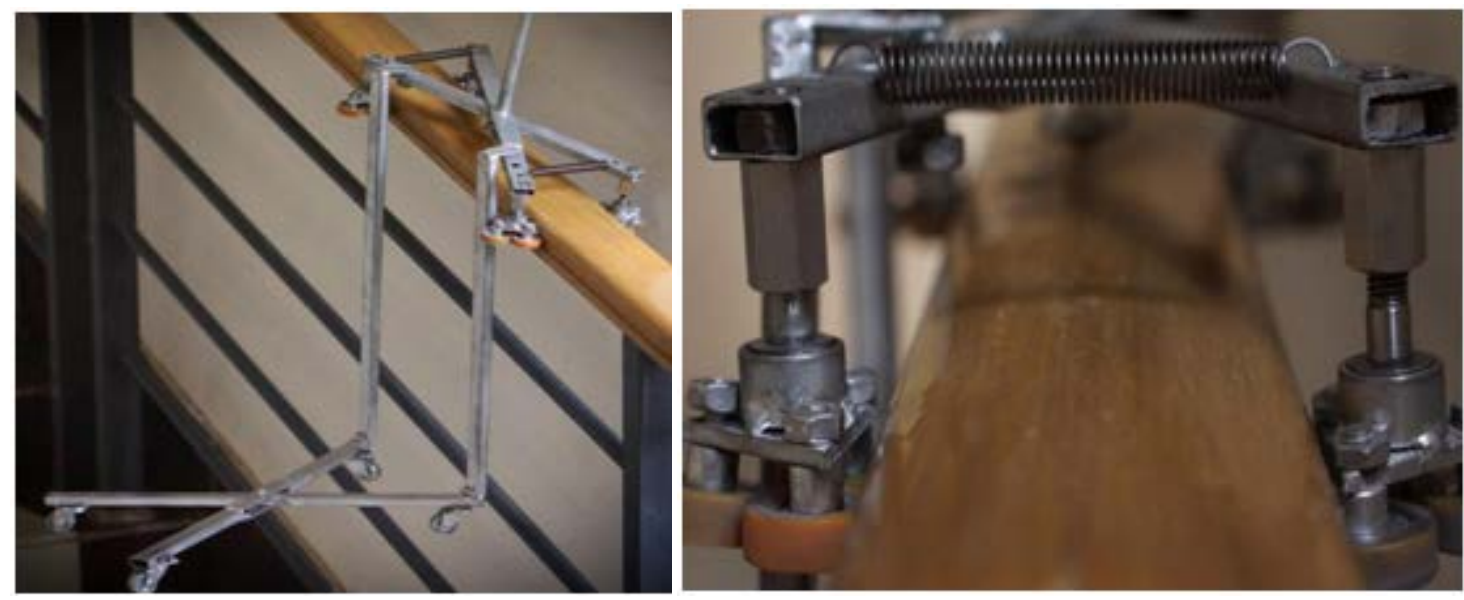

Fig.2The picture of the device

\section{Principal Organs of the Device}

The Cargo Agency of the Device. The component 1 and the component 2 are connected by the rotating shaft. When the device works, the angle of the two components can reach 90degrees. The cargo device is similar to a parallelogram when deliver goods. When the device is during the non-working state, the angle can reach 0 degree to save space, so couriers can carry it easily. The cargo agency is shown in Fig.3. 


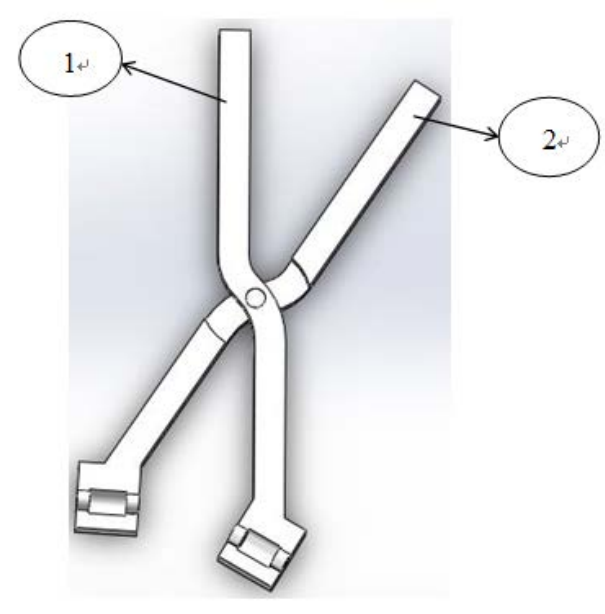

Fig.3The cargo agency

The Vertical Suspension Mechanism. On account of the gradient of the stair handrail is fixed. In order to ensure that goods which are shipped on the cargo agency still in level state,the length of the twovertical connecting rodsare different. The top of the two rodsare parallel to the stair handrail. The mechanical structure is shown in Fig.3.

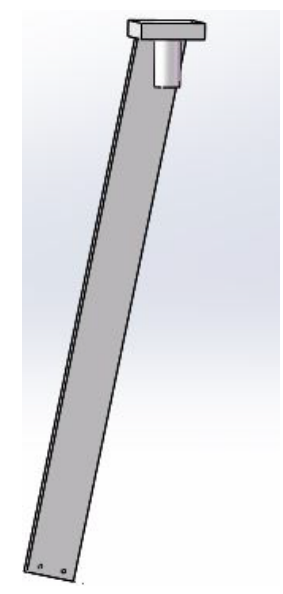

Fig.4The vertical suspension mechanism

Thehinge Connecting Mechanism. The cargo agency and the vertical suspension mechanism are connected by the hinge.When the device is in working state,the angle between the two mechanismsisninety degrees. When the device is in a state of non-working, they can be folded together.It is convenientfor couriers to carry, and it can save a lot of space.The hinge connecting mechanism is shown in Fig.5.

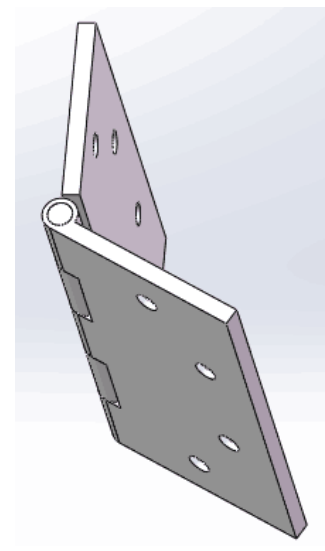

Fig.5The hinge 
The Fixed Device. The fixed device can be fixed on both sides of the stairs. In the middle of the device there is the ratchetmechanism. What's more, couriersdrive the whole device by the handle. The fixed deviceis shown in Fig.7.

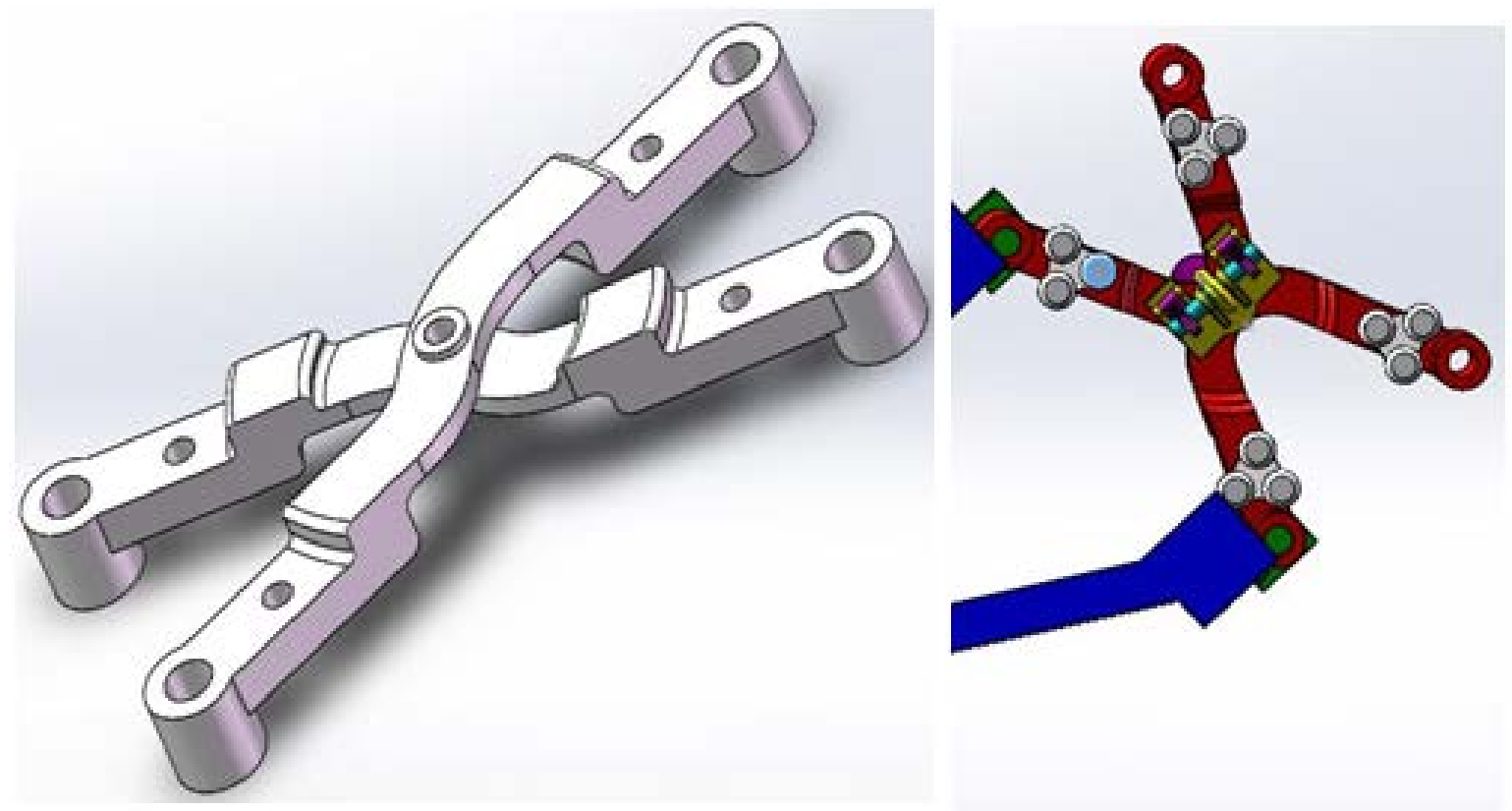

Fig.6The fixed device

The ratchet and the Brake Mechanism. To avoid the device slipping off the stair handrail, the ratchetwheels which move unidirectional are fixed under the fixed device. The pawl and the rack are fixed on the ratchet wheels. When the couriers move the goods upward, the pawl is flicked, so the pawl and the ratchet are connected to prevent the device from sliding off. When the couriers move the goods upward, the pawl and the ratchet are not connected. The device can slide along thestair handrail easily. In addition, the brake mechanism can stop the device at any time. The ratchetmechanism is shown in Fig.7.
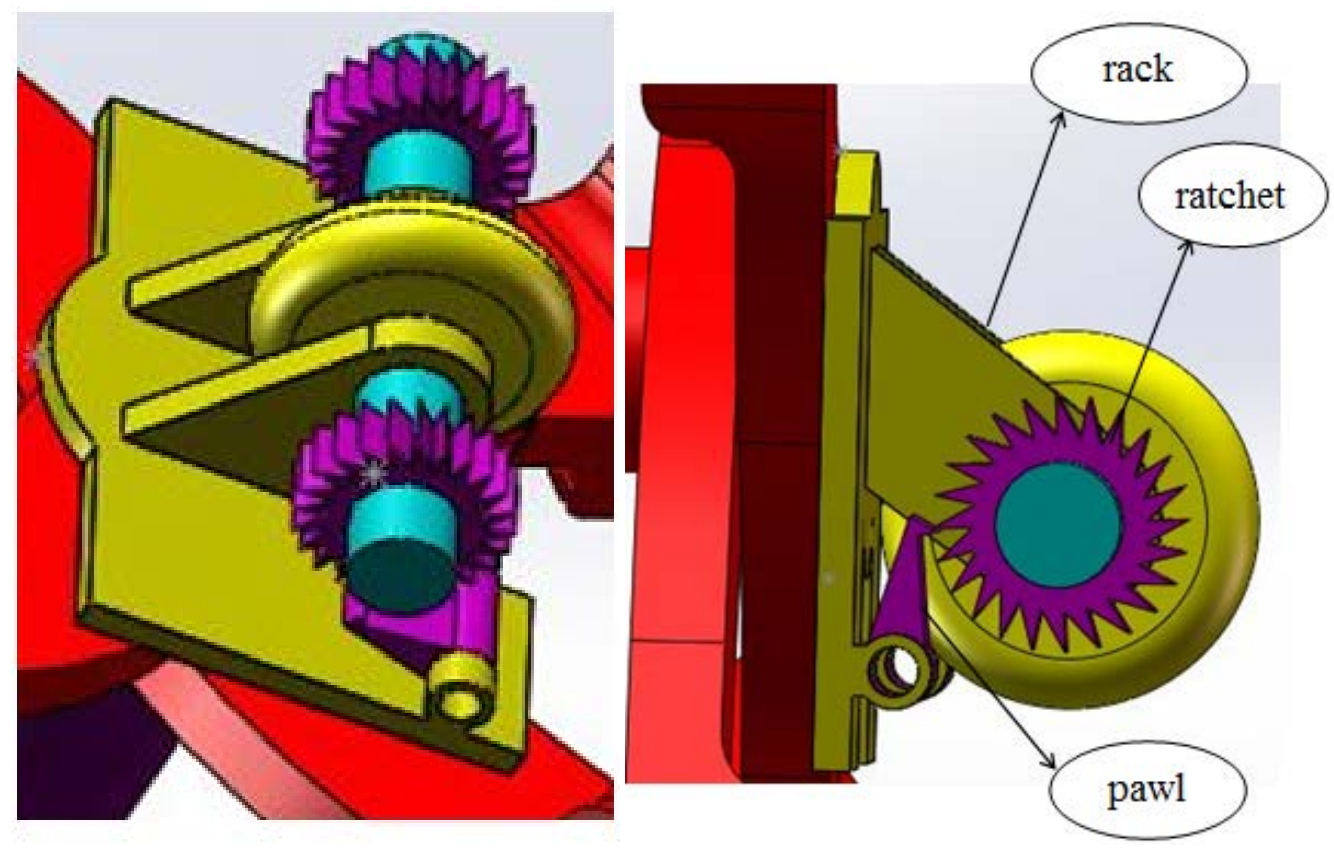

Fig.7The ratchetmechanism 
The Theoretical Arithmetic. The stress analysis of the device is necessary to judge the stability of the device.When the cargo is 20 kilos or 33 kilos, the stress of the device is analysis by SolidWorks, the stress analysis diagram is as follows:
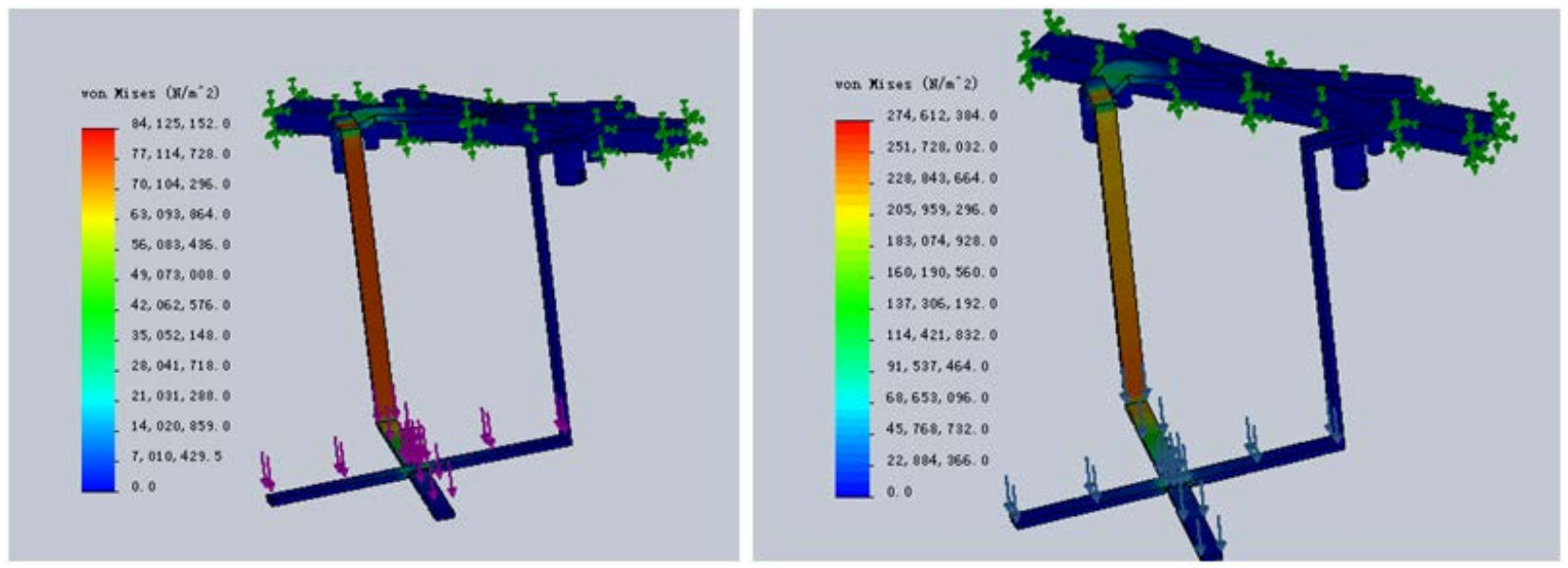

Fig.8The stress analysis of the device

FromFig.8, we can easily draw the conclusion that thetension strength is about 246347265 $\mathrm{N} / \mathrm{m}^{\wedge} 2$. Thetension strength of the alloy steel from the datasheet is $723825600 \mathrm{~N} / \mathrm{m}^{\wedge} 2$.So, we can conclude that the device meets the requirements of strength.

\section{Conclusion}

The device has the following innovation points:

Lighten the working strength of couriers by means of the device based on the stair handrail.

The device can not only transport goods on the playground, but also transport based on the stair handrail.

The fixed device, the ratchet and the brake mechanism enhance the safety.

The device is of great portability, and the price is cheap. So it has greatly popularized value.

\section{References}

[1] Yang Kezhen, Cheng guangyun, Li Zhongsheng,Basis of Mechanical Designing, Higher Education Press. 2013;

[2] Editorial board machine design manual,Machinery Handbook.China Machine Press, 2004;

[3] Fan Chongluo, Mechanical Processing Technology,Southeast University Press.2009;

[4] Zou Huijun.Mechanical Principle,Higher Education Press, 2006;

\section{通讯信息:}

\section{联系人高长青电话 13391797087}

\section{地址: 山东省滨州市无棣小泊头镇南高村（顺丰、中通、申通）}

\section{邮编: 251900}

